\title{
Structure, Function and Regulation of the Hsp90 Machinery
}

\author{
Jing $\mathrm{Li}^{1}$, Johannes Buchner ${ }^{2}$
}

\begin{abstract}
Heat shock protein 90 (Hsp90) is an ATP-dependent molecular chaperone which is essential in eukaryotes. It is required for the activation and stabilization of a wide variety of client proteins and many of them are involved in important cellular pathways. Since Hsp90 affects numerous physiological processes such as signal transduction, intracellular transport, and protein degradation, it became an interesting target for cancer therapy. Structurally, Hsp90 is a flexible dimeric protein composed of three different domains which adopt structurally distinct conformations. ATP binding triggers directionality in these conformational changes and leads to a more compact state. To achieve its function, Hsp90 works together with a large group of cofactors, termed co-chaperones. Co-chaperones form defined binary or ternary complexes with $\mathrm{Hsp} 90$, which facilitate the maturation of client proteins. In addition, posttranslational modifications of Hsp90, such as phosphorylation and acetylation, provide another level

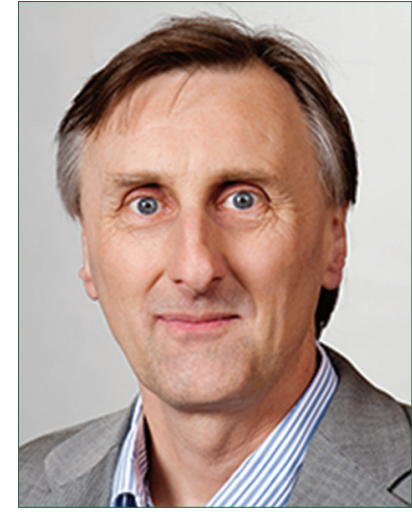

Prof. Johannes Buchner of regulation. They influence the conformational cycle, co-chaperone interaction, and inter-domain communications. In this review, we discuss the recent progress made in understanding the Hsp90 machinery. (Biomed J 2013;36:106-117)
\end{abstract}

\section{Key words: ATPase, clients, co-chaperones, conformational cycle, Hsp90, posttranslational modifications}

$\mathrm{H}$ eat shock protein 90 (Hsp90), one of the most abundant and conserved molecular chaperones, is essential in eukaryotic cells. ${ }^{[1,2]}$ Different from other well-known molecular chaperone like Hsp70 and GroEL/ES, Hsp90 is not required for de novo folding of most proteins but facilitates the final maturation of a selected clientele of proteins. ${ }^{[3]}$ Hsp90 clients include protein kinases, transcription factors such as $\mathrm{p} 53$, and steroid hormone receptors (SHRs). ${ }^{[4-7]}$ Therefore, Hsp90 does not only function in protein folding but also contribute to various cellular processes including signal transduction, intracellular transport, and protein degradation.

Interestingly, while bacteria possess an Hsp90 protein, called HtpG in Escherichia coli, no Hsp90 gene has been found in archea. ${ }^{[8-10]}$ However, bacterial Hsp90 is not essential and its precise function remains to be investigated. Recent studies suggest that it collaborates with the DnaK (Hsp70) system in substrate remodeling and may function against oxidative stress. ${ }^{[11,12]}$ In yeast, there are two
Hsp90 isoforms in the cytosol, Hsc82 and Hsp82, of which Hsp82 is up-regulated up to 20 times under heat stress. ${ }^{[2]}$ Hsp90 $\alpha$ and Hsp90 $\beta$ are the two major isoforms in the cytoplasm of mammalian cells. Hsp90 $\alpha$ is inducible under stress conditions, while Hsp90 $\beta$ is constitutively expressed. ${ }^{[13]}$ Hsp90 analogues also exist in other cellular compartments such as Grp94 in the endoplasmic reticulum, Trap-1 in the mitochondrial matrix, and ch-Hsp90 in the chloroplast. ${ }^{[14-16]}$ Interestingly, Hsp90 can be secreted as well and it promotes tumor invasiveness. Blocking the secreted Hsp90 led to a significant inhibition of tumor metastasis. ${ }^{[17]}$

\section{Structure of Hsp90}

Structurally, Hsp90 is a homodimer and each protomer contains three flexibly linked regions, an $\mathrm{N}$-terminal ATP-binding domain (N-domain), a middle domain (M-domain), and a C-terminal dimerization domain (C-domain) [Figure 1]. ${ }^{[18]}$ Except for the charged linker located

From the ${ }^{1}$ Division of Biology, California Institute of Technology, Pasadena, California, USA; ${ }^{2}$ Center for Integrated Protein Science, Department of Chemistry, Technische Universität München, Munich, Germany

Received: Sep. 5, 2012; Accepted: Nov. 2, 2012

Correspondence to: Prof. Johannes Buchner, Center for Integrated Protein Science, Department of Chemistry, Technical University of Munich. Lichtenbergstrasse 4, 85747 Garching, Germany. Tel: 49-89-28913341; Fax: 49-89-28913345; E-mail: johannes.buchner@ tum.de

DOI: $10.4103 / 2319-4170.113230$ 
between the $\mathrm{N}$ - and M-domains in eukaryotic Hsp90, this domain organization is conserved from bacteria to man. Hsp90 is a member of a special class of structurally related, evolutionarily conserved split ATPases, the so-called Gyrase, Hsp90, Histindine Kinase, MutL (GHKL) domain ATPases, which contain a Bergerat ATP-binding fold. ${ }^{[19]}$ Another interesting feature of the ATP binding region is that several conserved amino acid residues form a "lid" that closes over the nucleotide binding pocket in the ATP-bound state but is open during the ADP-bound state. ${ }^{[18]}$ The M-domain of Hsp90 is involved in ATP hydrolysis, as it contains crucial catalytic residues for forming the composite ATPase site. Moreover, the M-domain contributes to the interaction sites for client proteins and some co-chaperones. ${ }^{[20]}$ The C-domain is essential for the dimerization of Hsp90. Interestingly, in eukaryotic Hsp90, the opening of the C-domains is anticorrelated to the closing of the $\mathrm{N}$-domain. ${ }^{[21]} \mathrm{A}$ conserved MEEVD motif at the C-terminal end serves as the docking site for the interaction with co-chaperones which contain a tetratricopeptide repeat (TPR) clamp. ${ }^{[22]}$

\section{Conformational dynamics of Hsp90}

Hsp90 is a weak ATPase and the turnover rates are very low, with $1 \mathrm{~min}^{-1}$ for yeast Hsp90 and $0.1 \mathrm{~min}^{-1}$ for human Hsp90. ${ }^{[23-25]}$ Structural studies revealed that Hsp90 spontaneously adopts structurally distinct conformations, which seem to be in a dynamic equilibrium [Figure 1]. ${ }^{[9,26]}$ Nucleotide binding induces directionality and a conformational cycle. ${ }^{[9,27,28]}$ In the apo state, Hsp90 adopts a "V"-shaped form, termed "open conformation" [Figure 1]. ATP binding triggers a series of conformational changes including repositioning of the N-terminal lid region and a dramatic change in the N-M domain orientation. Finally, Hsp90 reaches a more compact state, termed "closed conformation" in which the N-domains are dimerized [Figure 1]. ${ }^{[9,18]}$ Recent biophysical studies using ensemble and single molecule fluorescence resonance energy transfer (FRET) assays allowed to further dissect the ATP-induced conformational changes [Figure 2]. ${ }^{[26,28]}$ After fast ATP binding, Hsp90 slowly reaches the first intermediate state (I1), in which the ATP lid is closed but the N-domains are still open. The N-terminal dimerization leads to the formation of the second intermediate state (I2), in which the $\mathrm{M}$-domain repositions and interacts with the $\mathrm{N}$-domain. Then Hsp90 reaches a fully closed state in which ATP hydrolysis occurs. After ATP is hydrolyzed, the N-domains dissociate, release ADP as well as inorganic phosphate (Pi), and Hsp90 returns to the open conformation again. ${ }^{[28]}$

Notably, nucleotide binding is not the only determinant for Hsp90 conformation. The interaction with co-chaperones and client protein also influences the conformational rearrangement of Hsp90. ${ }^{[29,30]}$ These results suggest that there may be a dynamic equilibrium between the different conformations of Hsp90 and this conformational plasticity is functionally important since it may allow Hsp90 to adapt to different client proteins.

\section{Co-chaperone regulation of Hsp90}

Co-chaperone regulation is a conserved feature of the eukaryotic Hsp90 system. To date, more than 20 co-chaperones have been identified. ${ }^{[1,31]}$ They regulate the function of Hsp90 in different ways such as inhibition and activation of the ATPase of Hsp90 as well as recruitment of specific client

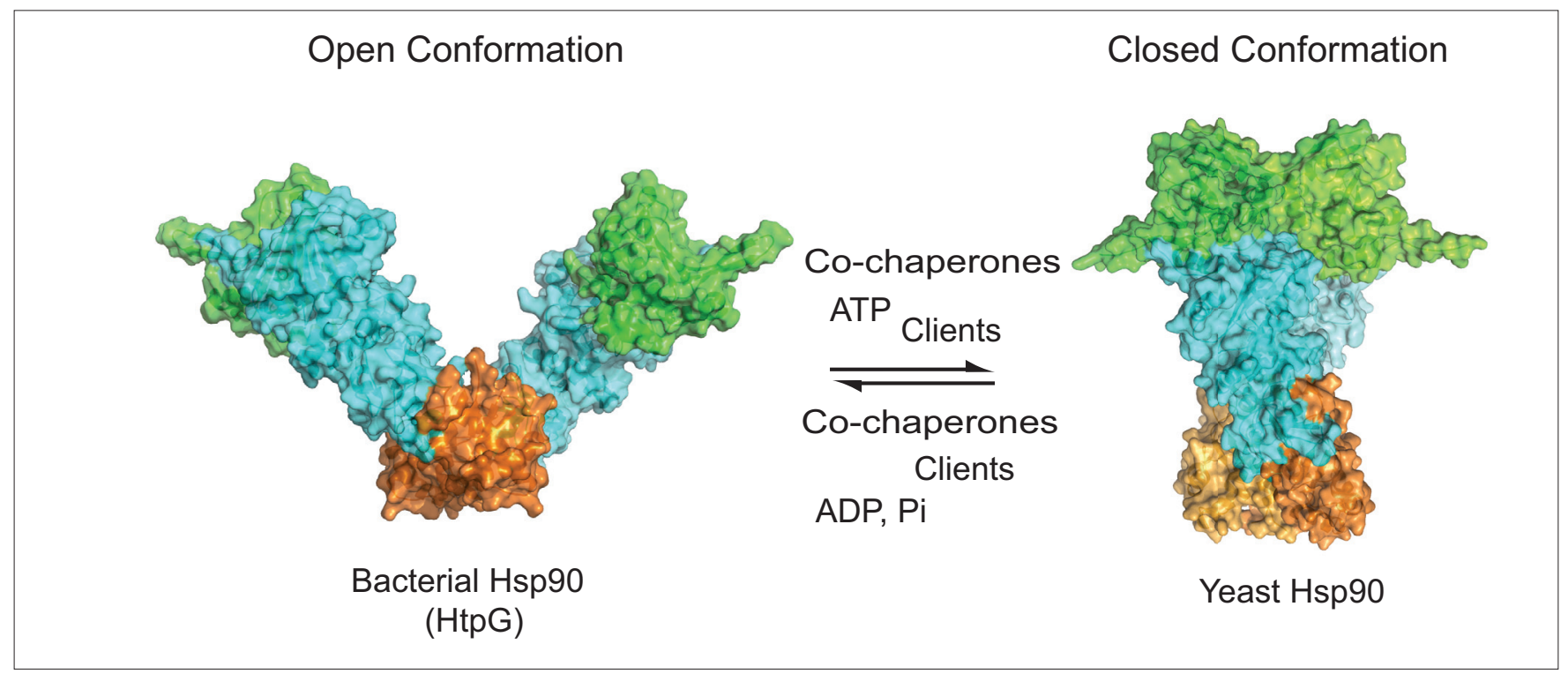

Figure 1: Open and closed conformation of Hsp90. Crystal structures of full-length Hsp90 from E. coli (HtpG) in the open conformation (left, PDB 2IOQ) and nucleotide-bound yeast Hsp90 in the closed conformation (right, PDB 2CG9). The N-domain is depicted in green, the $\mathrm{M}$-domain in blue, and the $\mathrm{C}$-domain in orange. 


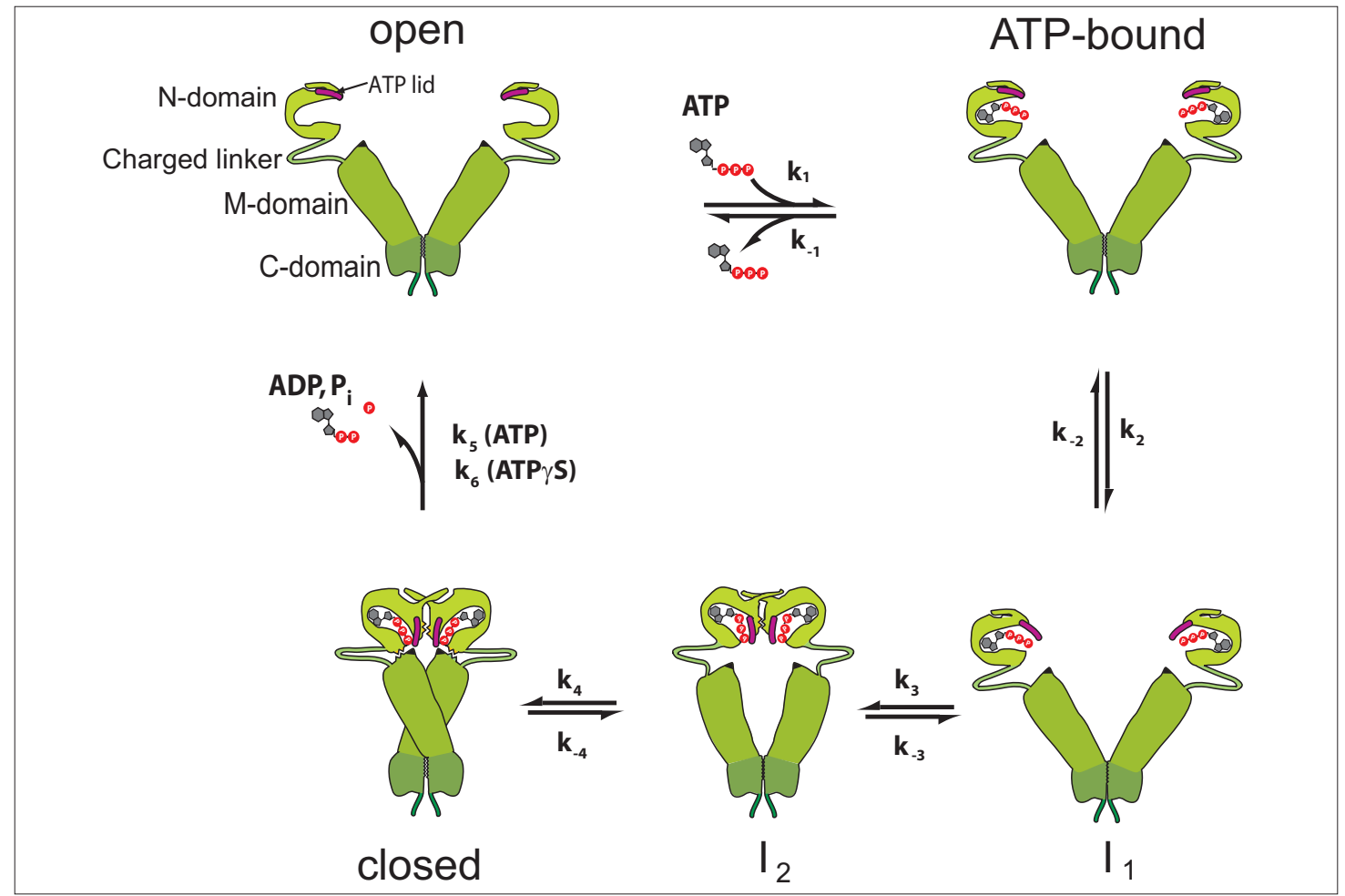

Figure 2: Conformational cycle of Hsp90. After fast ATP binding, Hsp90 slowly reaches the first intermediate state (I1), in which the ATP lid is closed but the $\mathrm{N}$-domains are still open. Then, the N-terminal dimerization leads to the formation of the second intermediate state (I2), in which the M-domain repositions and interacts with the N-domain. Then, Hsp90 reaches a fully closed state in which ATP hydrolysis occurs. After ATP is hydrolyzed, the N-domains dissociate, release ADP and Pi, and Hsp90 returns to the open conformation.

proteins to the cycle. Interestingly, different co-chaperones work together to facilitate the maturation of Hsp90 clients. ${ }^{[32]}$ The composition of co-chaperone complexes seems to depend to some degree on the presence of a specific client protein.

\section{The chaperone cycle for SHRs}

Early work on Hsp90 mainly focused on the co-chaperone requirement for the activation of SHRs. ${ }^{[32,33]}$ The maturation of most SHRs strictly depends on the interaction with Hsp90. Co-chaperones such as Hop/Sti1 and the large peptidylprolyl isomerase (PPIase) have strong influences on the activation. ${ }^{[32,34]}$ Research on the assembly of Hsp90 with SHRs had shown that several distinct complexes are formed during the maturation processes ${ }^{[32,35,36]}$ According to reconstitution experiments, SHRs must pass through three complexes with different co-chaperone compositions chronologically to reach their active conformation. Hsp70/Hsp40 were identified as components in the "early complex." [32] After association with Hsp90 through the adaptor protein Hop, the "intermediate complex" is formed. ${ }^{[37,38]}$ In addition to the intermediate complex, a third complex that contains a PPIase and the co-chaperone p 23 had been found as the last step of the cycle. ${ }^{[39-41]}$ Notably, similar heterocomplexes can be found from yeast to man even in the absence of client protein ${ }^{[32]}$ Recent studies [using FRET, analytical ultracentrifugation (aUC), nuclear magnetic resonance (NMR) spectroscopy, and electron microscopy] provided insight into how the exchange of co-chaperones is regulated. ${ }^{[42-44]}$ Based on these results, a new model of the chaperone cycle emerges [Figure 3A], in which first one Hop/Stil binds to the Hsp90 dimer and stabilizes its open conformation. As a result, the Hsp90 ATPase activity is inhibited. The other TPR-acceptor site is then preferentially occupied by a PPIase, leading to an asymmetric Hsp90 intermediate complex. After the binding of ATP and p23/Sba1, Hsp90 adopts the "closed" conformation which weakens the binding of Hop/ Sti1 and therefore promotes its exit. Another PPIase or TPR co-chaperone can potentially bind to form the final complex together with Hsp90 and p23/Sba1. Following ATP hydrolysis, p23/Sba1, PPIase, and the folded client are released from Hsp90. ${ }^{[42]}$

Hop/Sti1 serves as an adaptor protein between Hsp70 and Hsp90 and facilitates the transfer of client protein. ${ }^{[37,38]}$ Therefore, it is indispensable for maintaining the hormone binding activity of the glucocorticoid receptor (GR) and progesterone receptor (PR). ${ }^{[45,46]}$ Notably, Hop/Sti1 is a member of the large group of TPR co-chaperones. They contain a specialized conserved TPR-clamp domain, which consists of three TPR motifs and recognizes the C-terminal 


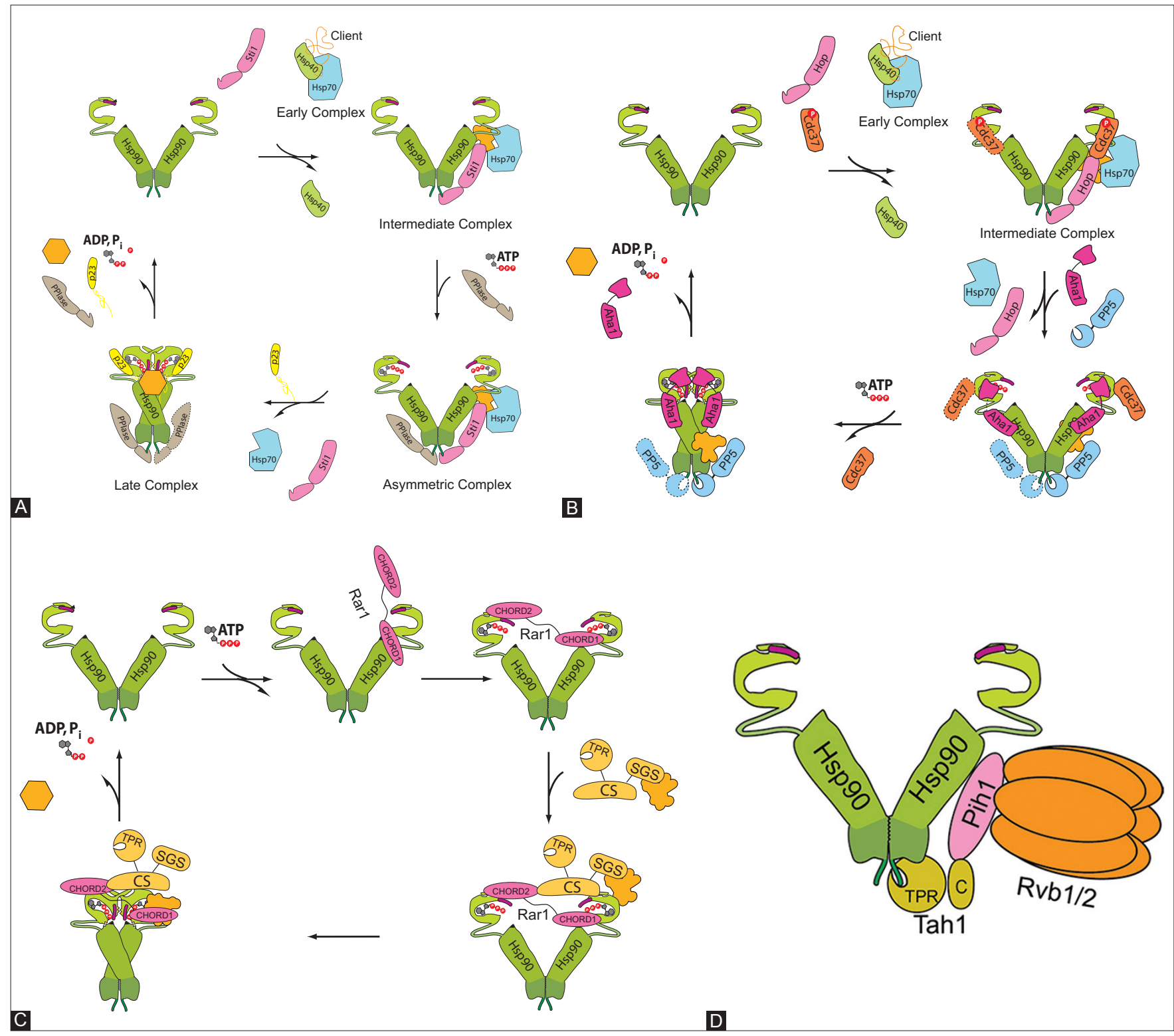

Figure 3: Hsp90 chaperone cycles. (A) Hsp90 chaperone cycle for SHRs. Hsp70, Hsp40, and a client protein form an "early complex.” The client protein is transferred from Hsp70 to Hsp90 through the adaptor protein Hop/Sti1. One Hop/Sti1 bound is sufficient to stabilize the open conformation of Hsp90. The other TPR-acceptor site is preferentially occupied by a PPIase, leading to an asymmetric intermediate complex. Hsp90 adopts the ATPase-active (closed) conformation after binding of ATP. p23/Sba1 stabilizes the closed state of Hsp90, which weakens the binding of Hop/Sti1 and promotes its exit from the complex. Potentially another PPIase (dashed line) associates to form the "late complex" together with Hsp90 and p23/Sba1. After the hydrolysis of ATP, p23/Sba1 and the folded client are released from Hsp90. (B) Hsp90 chaperone cycle for kinases. In the early stage, Hsp70 and Hsp40 interact with newly synthesized kinases. Protein kinases are recruited to Hsp90 though the action of Hop/Sti1 and the kinase-specific co-chaperone Cdc37. Both are able to stabilize the Hsp90/kinase complex. Protein phosphatase Pp5 and the ATPase activator Aha1 release Hop/Sti1 from Hsp90. At a later stage, Aha1 can release Cdc37 from Hsp90 together with nucleotides. (C) Hsp90 chaperone cycle for NLRs. Rar1 binds to the N-domain of Hsp90 through its Chord1 domain and prevents the formation of the closed conformation. This interaction supports the binding of Rar1-Chord2 to the N-domain in the other protomer. With the association of Rar1-Chord2, Sgt1 interacts with Hsp90 as well as with an NLR protein. In the stable ternary complex, the lid segment promotes ATP hydrolysis. Once ATP is hydrolyzed, Rar1, Sgt1, and the NLR protein may dissociate from Hsp90. (D) Hsp90-R2TP complex. Model of the R2TP complex in yeast. Pih1 interacts with Rvb1/2, with the M-domain of Hsp90, and the C-domain of Tah1. Tah1 binds to the C-terminal MEEVD motif of Hsp90 through its TPR domain.

MEEVD motif in Hsp90. ${ }^{[22]}$ Besides Hop/Sti1, the protein phosphatase PP5 (yeast homologue Ppt1), and members of the PPIase family, like Fkbp52, Fkbp51, and Cyp40 (yeast homologues Cpr6/Cpr7), belong to this group.

The TPR-containing PPIases contain a PPIase domain, which catalyzes the interconversion of the cis-trans isomeriza- 
tion of peptide bonds prior to proline residues ${ }^{[47]}$ and a TPR domain for the interaction with Hsp90. Most of these large PPIases show independent chaperone activity. ${ }^{[48-50]}$ However, the function of PPIases in SHR complexes is not well understood. They may be selected by specific client proteins. For example, Cyp40 is most abundant in estrogen receptor (ER) complexes $^{[51]}$ and Fkbp52 mediates potentiation of GR through increasing GR hormone-binding affinity. ${ }^{[34]}$ Interestingly, the potentiation effects do not strictly depend on the PPIase activity of Fkbp52 as PPIase-deficient mutants are also able to potentiate GR transactivation, which suggests a noncatalytic role of PPIases in the regulation of SHR signaling. ${ }^{[52]}$

In contrast to Hop/Sti1 and the TPR-PPIases, p23 is a conformation-specific co-chaperone which binds exclusively to the closed conformation of Hsp90. ${ }^{[53,54]}$ This small acidic protein contains an unstructured C-terminal tail, which is essential for its intrinsic chaperone activity. ${ }^{[55,56]}$ p23 was identified as a component in SHR complexes, together with Hsp90 and a PPIase. ${ }^{[57]}$ It facilitates the maturation of client proteins by stabilizing the closed conformation of Hsp90. ${ }^{[58]}$ As a result, the ATP hydrolysis, which is indispensable for the release of the client protein, ${ }^{[59-61]}$ is partially inhibited in the presence of $\mathrm{p} 23 / \mathrm{Sba} 1 .^{[41,62]}$

\section{Chaperone cycle for protein kinases}

Similar to SHRs, the maturation of protein kinases also requires the Hsp70 chaperone machinery [Figure 3B]. ${ }^{[63]}$ In the early stage, Hsp70 and Hsp40 interact with newly synthesized kinases. Protein kinases are recruited to Hsp90 through the action of Hop/Stil and the kinase-specific co-chaperone Cdc37. Both are able to stabilize the Hsp90/ kinase complex. ${ }^{[64]}$ At a later stage, the ATPase activator Aha1 can release Cdc37 from Hsp90, together with nucleotides ${ }^{[65]}$ which leads to the final activation of protein kinases.

$\mathrm{Cdc} 37$ is specific for chaperoning kinases. ${ }^{[66,67]}$ It was originally identified in Saccharomyces cerevisiae as a gene essential for cell cycle progression. ${ }^{[68,69]} \mathrm{Cdc} 37$ interacts with kinases through its $\mathrm{N}$-terminal domain and binds to the N-domain of Hsp90 via its C-terminal part. Similar to Hop/Sti1, the interaction of Cdc37 with Hsp90 leads to the stabilization of the open conformation and the inhibition of Hsp90 ATPase activity. ${ }^{[70]}$

In contrast to the co-chaperones discussed above, Aha1 is the most powerful ATPase activator of Hsp90. ${ }^{[71]}$ It binds the N- and M-domains of Hsp90. ${ }^{[20,30]}$ Binding of Aha1 induces a partially closed Hsp90 conformation and accelerates the progression of the ATPase cycle dramatically. ${ }^{[28,30]}$ The presence of Aha1 enables Hsp90 to bypass the I1 state and to directly reach I2 in the ATPase cycle. ${ }^{[28]}$ The activation of specific clients such as viral Src kinase ( $\mathrm{v}-\mathrm{Src})$ and SHRs is severely affected in Aha1 knockout cells. ${ }^{\left[{ }^{[72}\right]}$ Moreover, Aha1 plays a critical role in the inherited misfolding disease cystic fibrosis (CF) through participating in the quality control pathway of the cystic fibrosis transmembrane conductance regulator (CFTR). Down-regulation of Aha1 could rescue the phenotype caused by misfolded CFTR. ${ }^{[73]}$ Recent research highlighted the function of Aha1 in the progression of the Hsp90 cycle. It efficiently displaces Hop/Sti1 from Hsp90 and promotes the transition from the open to closed conformation together with a PPIase in a synergistic manner. ${ }^{[74]}$

Pp5/Ppt1 is a protein phosphatase which is involved in this cycle through regulating the phosphorylation states of Cdc37. It associates with Hsp90 through its N-terminal TPR domain. Binding to Hsp90 results in the abrogation of the intrinsic inhibition of Pp5/Ppt1. ${ }^{[75]} \mathrm{Pp} 5 / \mathrm{Ppt} 1$ specifically dephosphorylates Hsp90 and Cdc37 in Hsp90 complexes. ${ }^{[76,77]}$ In Ppt1 knockout strains, the activity of Hsp90-specific clients is significantly reduced, which implies that the tight regulation of the Hsp90 phosphorylation state is necessary for the efficient processing of client proteins. ${ }^{[76]}$

\section{Chaperone cycle for nucleotide-binding site and} leucine-rich repeat domain containing (NLR) proteins

NLRs are conserved immune sensors which recognize pathogens. ${ }^{[78]}$ Accumulating evidence indicates that Hsp90 and its co-chaperones Sgt1 and Rar1 are involved in the maturation of these proteins. ${ }^{\left[{ }^{[9]}\right.}$ Sgt1 interacts with the $\mathrm{N}$-domain of Hsp90 through its CS domain, which is structurally similar to p23/Sba1 ${ }^{[80,81]}$ However, Sgt1 has no inherent Hsp90 ATPase regulatory activity due to differences in interaction. ${ }^{[81]}$ Interestingly, although a TPR domain is present in Sgt1 as well, it is not involved in the interaction with Hsp90 ${ }^{[82]}$ Functionally, Hsp90 and Sgt1 form a ternary complex with the co-chaperone Rar1, which acts as a core modulator in plant immunity. ${ }^{[78]}$

During the recruitment and activation of NLRs, Rar1 binds to the N-domain of Hsp90 through its Chord1 domain and prevents the formation of the closed conformation [Figure 3C]. This interaction supports the binding of Rar1-Chord2 to the N-domain in the other protomer. With the association of Rar1-Chord2, Sgt1 is promoted to interact with Hsp90 as well as with an NLR protein. In the stable ternary complex, the lid segment is very flexible, thus permitting access by a catalytic arginine residue of the M-domain to the ATP binding site and promoting ATP hydrolysis. Once ATP is hydrolyzed, Rar1, Sgt1, and the NLR protein may dissociate from Hsp90. ${ }^{[83]}$

\section{Hsp90 complexes in RNA processing}

Recent studies showed that Hsp90 is also involved in the assembly of small nucleolar ribonucleoproteins (snoRNPs) and RNA polymerase. ${ }^{[84-86]}$ The chaperone cycle is not com- 
pletely understood yet. However, the central player in this process, the R2TP complex (consisting of Tah1, Pih1, and the AAA+ ATPase Rvb1 and Rvb2) has been extensively investigated [Figure 3D]. ${ }^{[86,87]}$

The co-chaperone Tah1 interacts with Hsp90 through its TPR domain and its C-terminal region binds Pih1, an unstable non-TPR co-chaperone of Hsp90 [Figure 3D]. During the maturation of snoRNP, the Hsp90-Tah1 complex stabilizes Pih1 in vivo and prevents its aggregation in vitro. ${ }^{[84]}$ The Tah1-Pih1 heterodimer is able to inhibit the ATPase activity of Hsp90. ${ }^{[88]}$ Tah1 and Pih1 are then transferred to the Rvb1/2 complex leading to the formation of the R2TP complex [Figure 3D]. Together, Hsp90 and the R2TP complex are involved in the biogenesis and assembly of snoRNPs. Notably, neither Hsp90 nor R2TP are components of the mature snoRNP complex. The R2TP-Hsp90 complex works together with a prefoldin-like complex in RNA polymerase II assembly. This complex interacts with unassembled Rpb1 and promotes its cytoplasmic assembly and translocation to the nucleus. ${ }^{[85]}$

In addition to the activation of client protein, co-chaperones are also involved in other physiological processes, such as mitochondrial/chloroplast protein import (Tom70/ Toc64), ${ }^{[89,90]}$ nuclear migration (NudC), ${ }^{[91]}$ and melanoma progression (TTC4). ${ }^{[92]}$ The above examples provide a glimpse on Hsp90 co-chaperone cycles. For some cycles, we have obtained a full picture with detailed information; for others, we just start to understand their contributions to client protein activation.

\section{Regulation of Hsp90 by posttranslational modifications}

Posttranslational modifications are another important regulatory element of the Hsp90 machinery. Different posttranslational modifications such as phosphorylation, acetylation, nitrosylation, and methylation tightly control the function of Hsp90 and thus influence the maturation of client proteins. ${ }^{[93]}$

\section{Phosphorylation}

Phosphorylation is the most frequently detected posttranslational modification of Hsp90. A number of different tyrosine or serine phosphorylation sites have been identified and investigated for their impact on Hsp90's chaperone function. ${ }^{[94]}$ For example, only phosphorylated Hsp90 stimulates the activity of the Hsp90 client protein heme-regulated inhibitor kinase (HRI); dephosphorylation eliminated the ability of Hsp90 to activate this client protein. ${ }^{[95]}$ Interestingly, hyperphosphorylation also leads to a decreased Hsp90 activity. In yeast, the protein phosphatase Ppt1 deletion compromised the activation of specific clients. ${ }^{[76]}$ Therefore, the phosphorylation states of Hsp90 must be precisely regulated in order to maintain the proper function of Hsp90. In addition, phosphorylation also modulates the interaction with co-chaperones and thus exerts further influence on the Hsp90 machinery ${ }^{[96]}$ For example, tyrosine phosphorylation on Hsp90 disrupts the interaction with $\mathrm{Cdc} 37$ and promotes the recruitment of Aha1. ${ }^{[97]} \mathrm{C}$-terminal phosphorylation of Hsp90 regulates alternate binding to co-chaperones Chip and Hop, which determine cellular protein folding/degradation balances. ${ }^{[98]}$ Furthermore, phosphorylation affects the conformational cycle of Hsp90, such as formation of the active sites, general flexibility, and inter-domain communication. ${ }^{[96,99]}$

A number of different kinases can phosphorylate Hsp90, such as double-stranded DNA protein kinase, c-Src kinase, protein kinase A (PKA), CK2 protein kinase, and Swe1Wee1 kinase. ${ }^{[100-103]}$ Interestingly, many of them are at the same time Hsp90 client proteins. This indicates that the change of phosphorylation states of Hsp90 may influence the folding and activation of certain groups of client proteins.

\section{Acetylation}

Acetylation is a reversible modification mediated by opposing actions of acetyltransferases and deacetylases. ${ }^{[104]}$ Hsp90 acetylation and its influence on the chaperone machinery have been extensively investigated in recent years. In the case of Hsp90, p300 was reported to be the acetyltransferase and HDAC6 acts as a deacetylase which removes the acetyl group from the protein. ${ }^{[105,106]}$ Deacetylation of Hsp90 drives the formation of Hsp90 client complexes and promotes the maturation of the client protein GR. Hsp90 can be acetylated at different sites. ${ }^{[107]} \mathrm{A}$ study from Necker's lab pointed out that K294, an acetylation site in the M-domain, strongly influences the binding between Hsp90 and its client protein. In general, acetylation weakens Hsp90-client interaction, and thus, Hsp90 fails to support the activation of the client protein. ${ }^{[108]}$

\section{Nitrosylation}

S-nitrosylation is a reversible covalent modification of reactive cysteine thiols in proteins by nitric oxide (NO). ${ }^{[109,110]}$ Mammalian Hsp90 is a target of S-nitrosylation mediated by NO produced by its client protein, endothelial nitric oxide synthase (eNOS). ${ }^{[111]} \mathrm{S}$-nitrosylation was reported as a negative regulator which inhibits the ATPase activity of Hsp90. ${ }^{[111]}$ In addition, the activation of its client protein, eNOS, was also reduced consistent with the notion thatHsp90 acts as an NO sensor. ${ }^{[111]}$ This provides a feedback mechanism to inhibit further eNOS activation. Nitrosylation or mutation of the modified C-terminal cysteine residue in Hsp90 led to an ATPase-incompetent state in which the $\mathrm{N}$-terminal domains are kept in the open conformation. ${ }^{[122]}$ The result indicates that nitrosylation has a profound impact on the inter-domain communication in the Hsp90 dimer. 


\section{Hsp90 client protein recognition}

To date, more than $200 \mathrm{Hsp} 90$ client proteins have been identified (see http://www.picard.ch/downloads/Hsp90interactors.pdf). Besides the well-studied clients such as protein kinases and SHRs, many others related to, for example, viral infection, innate immunity, and RNA modification, have been discovered in recent years. ${ }^{[84,113,114]}$ The interaction with the Hsp90 machinery enables their correct folding, activation, transport, and even degradation. ${ }^{[89,115-117]}$

Our understanding of the Hsp90 machinery has been greatly advanced by research of the last decades. However, some fundamental questions related to client proteins still remained unanswered, such as the location of the client-binding sites on Hsp90. Current evidence suggests that binding sites could be localized in each of the domains of Hsp90. ${ }^{[8]}$ Another intriguing question unsolved so far is how Hsp90 recognizes its clients. Hsp90 clients belong to different families and do not share common sequences or structural motifs. Although some regions were identified which are important for the recognition of certain group of clients, for example, the $\alpha \mathrm{C}-\beta 4$ loop in kinases, ${ }^{[118,119]}$ this is not the only determinant for the interaction as other regions adjacent to the kinase domain also influence the binding to Hsp90. ${ }^{[120,121]}$ It is reasonable to assume that Hsp90 recognizes certain conformations or the stability of the client protein rather than its primary sequence. Src kinase is a prominent example here. The $\mathrm{v}$-Src and its cellular counterpart (c-Src) share $95 \%$ sequence identity but distinct Hsp90 dependency. ${ }^{[122]}$ The activation of v-Src strictly depends on Hsp90, while c-Src is largely independent of Hsp90. ${ }^{[122]}$ Notably, v-Src is an aggregation-prone protein and much more sensitive to thermal and heat denaturation than $\mathrm{c}-\mathrm{Src} .{ }^{[123]} \mathrm{In}$ the case of $\mathrm{p} 53$, biochemical experiments suggest that p53 interacts with Hsp90 in a rather folded state. ${ }^{[124-126]}$ However, recent results imply that p53 may be destabilized by Hsp $90,{ }^{[127]}$ and NMR-based approaches suggested that for heat-treated p53, Hsp90 binds the largely unfolded protein. ${ }^{[128]}$ Park et al., proposed that Hsp90-bound p53 is in a molten globule state. ${ }^{[129]}$ In contrast, Hagn et al. reported a native-like structure of p53 interaction with Hsp90. ${ }^{[130]}$ Further analysis seems to be required to resolve this conundrum and to determine the molecular mechanism for client recognition.

\section{Hsp90 and protein degradation}

Although in general, Hsp90 stabilizes and promotes the correct folding of its client proteins, it was also found to facilitate protein degradation. In addition to soluble cytosolic proteins, several reports have shown that Hsp90 is also required for the degradation of ER membrane proteins such as cytochrome p450 2E1, mutant CFTR $\Delta$ F508, and apolipoprotein $B \cdot{ }^{[131-133]}$ Another aspect which supports the idea that Hsp90 may be involved in the ubiquitin-proteasome pathway is the discovery of a protein called carboxyl terminus of Hsp70-interacting protein (CHIP). ${ }^{[134]}$ As an E3 ubiquitin ligase, CHIP can ubiquitinate unfolded proteins. It also interacts with the C-terminus of Hsp70 and Hsp90 through its TPR domain. ${ }^{[135,136]}$ The CHIP knockdown is known to stabilize some Hsp90 clients, while its overexpression promotes their degradation. ${ }^{[137-139]}$ Recently, more E3 ligases have been found to be associated with Hsp90, such as Ubr1 and Cul5 which are involved in the quality control or degradation of different client proteins. ${ }^{[140,141]}$ However, aspects such as the selection of different ligases remain to be further elucidated.

\section{Hsp90 inhibitors and human diseases}

As many proteins which control cell survival, proliferation, and apoptosis are client proteins of Hsp90, Hsp90 function is closely related to human health. A number of reports have suggested that Hsp90 plays a crucial role in the progression of diseases. ${ }^{[142-145]}$ For example, the expression of Hsp90 is 2- to 10-fold higher in tumor cells than in normal cells. ${ }^{[146]}$ Therefore, Hsp90 has emerged as an important target in several diseases. Numerous natural and synthetic Hsp90 inhibitors have been developed in recent years, some of which exhibit excellent antitumor activities and have entered clinical trials. ${ }^{[141,144,147,148]}$

Geldanamycin (GA), a benzoquinone ansamycin antibiotic, is the first discovered Hsp90 inhibitor. It binds competitively to the ATP binding site in the N-domain of Hsp90 and thus prevents the conformational change of Hsp90. ${ }^{[149,150]}$ GA exhibits potent antitumor effects; however, due to the poor solubility and high toxicity, it cannot be used as a drug candidate. ${ }^{[151]}$ Different derivatives have been synthesized, such as 17-AAG, which is more hydrophilic and already showed success in preclinical and clinical studies. ${ }^{[152,153]}$

Radicicol (also known as monorden) is another natural product inhibitor of Hsp90, which is a 14-membered macrolide originally isolated from Monosporium bonorden..$^{[154]}$ Radicicol also acts as a nucleotide-mimicking compound and occupies the ATP binding pocket of Hsp90, but with a much higher affinity than ATP ${ }^{[154]}$ in vitro studies have shown that radicicol has potent anti-proliferation effects. ${ }^{[155]}$ However, in vivo studies did not reveal anti-tumor activities, which is probably due to its low biological stability. ${ }^{[156]}$

Besides these two, many new inhibitors have been found or synthesized. For example, radanamycin amide (radamide) was designed based on the co-crystallization structures of the GA/Hsp90 N-domain and the Radiciol/ Hsp90 N-domain. ${ }^{[149,157]}$ This chimeric compound contains both radicicol's resorcinol ring and the quinine ring from GA. It shows potent inhibition effects of $\mathrm{Hsp} 90$ in a low 
micromolar range in breast cancer cells. ${ }^{[157]} \mathrm{PU} 3$, a representative of purine-based inhibitor, binds to Hsp90 and inhibits the growth of breast cancer cells. ${ }^{[158]}$ Novobiocin, a coumarin antibiotic, was also identified as an Hsp90 inhibitor. ${ }^{[159]}$ Interestingly, novobiocin targets the C-terminal domain of Hsp90. ${ }^{[160]}$ More compounds with better inhibitory activity and less toxicity are currently designed and synthesized. ${ }^{[161]}$

Currently, there are more than 10 different Hsp90 inhibitors in various stages of clinical development, like IPI504, NVP-AUY922, and STA-9090. ${ }^{[162]}$ The results obtained so far look promising, but still several key questions need to be addressed. Like in basic research on Hsp90, significant progress has been made in recent years, but important questions remain to be solved. Prospects are very good that major breakthroughs will be achieved in the near future.

\section{Acknowledgment}

This work was supported by the Deutsche Forschungsgemeinschaft (grants SFB 594 A2 to JB) and the BMBF project ProNet-T3, and by the Fonds der chemischen Industrie.

\section{REFERENCES}

1. Taipale M, Jarosz DF, Lindquist S. HSP90 at the hub of protein homeostasis: Emerging mechanistic insights. Nat Rev Mol Cell Biol 2010;11:515-28.

2. Borkovich KA, Farrelly FW, Finkelstein DB, Taulien J, Lindquist S. Hsp82 is an essential protein that is required in higher concentrations for growth of cells at higher temperatures. Mol Cell Biol 1989;9:3919-30

3. Nathan DF, Vos MH, Lindquist S. in vivo functions of the saccharomyces cerevisiae Hsp90 chaperone. Proc Natl Acad Sci USA 1997;94:12949-56.

4. Zhao R, Davey M, Hsu YC, Kaplanek P, Tong A, Parsons AB, et al Navigating the chaperone network: An integrative map of physical and genetic interactions mediated by the Hsp90 chaperone. Cell 2005; 120:715-27.

5. Pratt WB, Toft DO. Steroid receptor interactions with heat shock protein and immunophilin chaperones. Endocr Rev 1997;18:306-60.

6. McClellan AJ, Xia Y, Deutschbauer AM, Davis RW, Gerstein M, Frydman J. Diverse cellular functions of the Hsp90 molecular chaperone uncovered using systems approaches. Cell 2007;131:121-35.

7. Picard D. Heat-shock protein 90, a chaperone for folding and regulation. Cell Mol Life Sci 2002;59:1640-8.

8. Buchner J. Bacterial Hsp90: Desperately seeking clients. Mol Microbiol 2010;76:540-4.

9. Shiau AK, Harris SF, Southworth DR, Agard DA. Structural analysis of E. Coli Hsp90 reveals dramatic nucleotide-dependent conformational rearrangements. Cell 2006;127:329-40.

10. Bardwell JC, Craig EA. Eukaryotic Mr 83,000 heat shock protein has a homologue in escherichia coli. Proc Natl Acad Sci U S A 1987;84:5177-81.
11. Steeves CH, Potrykus J, Barnett DA, Bearne SL. Oxidative stress response in the opportunistic oral pathogen Fusobacterium nucleatum. Proteomics 2011;11:2027-37.

12. Genest O, Hoskins JR, Camberg JL, Doyle SM, Wickner S. Heat shock protein 90 from Escherichia coli collaborates with the DnaK chaperone system in client protein remodeling. Proc Natl Acad Sci U S A 2011;108:8206-11.

13. Langer T, Rosmus $\mathrm{S}$, Fasold H. Intracellular localization of the 90 kDA heat shock protein (HSP90alpha) determined by expression of a EGFP-HSP90alpha-fusion protein in unstressed and heat stressed 3 T3 cells. Cell Biol Int 2003;27:47-52.

14. Felts SJ, Owen BA, Nguyen P, Trepel J, Donner DB, Toft DO. The hsp90-related protein TRAP1 is a mitochondrial protein with distinct functional properties. J Biol Chem 2000;275:3305-12.

15. Mazzarella RA, Green M. ERp99, an abundant, conserved glycoprotein of the endoplasmic reticulum, is homologous to the 90-kDa heat shock protein (hsp90) and the 94-kDa glucose regulated protein (GRP94). J Biol Chem 1987;262:8875-83.

16. Sorger PK, Pelham HR. The glucose-regulated protein grp94 is related to heat shock protein hsp90. J Mol Biol 1987;194:341-4.

17. Wang X, Song X, Zhuo W, Fu Y, Shi H, Liang Y, et al. The regulatory mechanism of Hsp90alpha secretion and its function in tumor malignancy. Proc Natl Acad Sci U S A 2009;106:21288-93.

18. Ali MM, Roe SM, Vaughan CK, Meyer P, Panaretou B, Piper PW, et al. Crystal structure of an Hsp90-nucleotide-p23/Sba1 closed chaperone complex. Nature 2006;440:1013-7.

19. Dutta R, Inouye M. GHKL, an emergent ATPase/kinase superfamily. Trends Biochem Sci 2000;25:24-8.

20. Meyer P, Prodromou C, Liao C, Hu B, Roe SM, Vaughan CK, et al. Structural basis for recruitment of the ATPase activator Aha1 to the Hsp90 chaperone machinery. EMBO J 2004;23:1402-10.

21. Ratzke C, Mickler M, Hellenkamp B, Buchner J, Hugel T. Dynamics of heat shock protein $90 \mathrm{C}$-terminal dimerization is an important part of its conformational cycle. Proc Natl Acad Sci U S A 2010;107:16101-6.

22. Scheufler C, Brinker A, Bourenkov G, Pegoraro S, Moroder L, Bartunik H, et al. Structure of tpr domain-peptide complexes: Critical elements in the assembly of the Hsp70-Hsp90 multichaperone machine. Cell 2000;101:199-210.

23. Richter K, Muschler P, Hainzl O, Buchner J. Coordinated ATP hydrolysis by the Hsp90 dimer. J Biol Chem 2001;276:33689-96.

24. Richter K, Soroka J, Skalniak L, Leskovar A, Hessling M, Reinstein J, et al. Conserved conformational changes in the atpase cycle of human Hsp90. J Biol Chem 2008;283:17757-65.

25. Mclaughlin SH, Smith HW, Jackson SE. Stimulation of the weak atpase activity of human Hsp90 by a client protein. J Mol Biol 2002;315:787-98.

26. Mickler M, Hessling M, Ratzke C, Buchner J, Hugel T. The large conformational changes of Hsp90 are only weakly coupled to ATP hydrolysis. Nat Struct Mol Biol 2009;16:281-6.

27. Graf C, Stankiewicz M, Kramer G, Mayer MP. Spatially and kinetically resolved changes in the conformational dynamics of the Hsp90 chaperone machine. EMBO J 2009;28:602-13.

28. Hessling M, Richter K, Buchner J. Dissection of the atp-induced conformational cycle of the molecular chaperone Hsp90. Nat Struct Mol Biol 2009;16:287-93. 
29. Street TO, Lavery LA, Agard DA. Substrate binding drives large-scale conformational changes in the Hsp90 molecular chaperone. Mol Cell 2011;42:96-105.

30. Retzlaff M, Hagn F, Mitschke L, Hessling M, Gugel F, Kessler H, et al. Asymmetric activation of the Hsp90 dimer by its cochaperone Aha1. Mol Cell 2010;37:344-54.

31. Li J, Soroka J, Buchner J. The Hsp90 chaperone machinery: Conformational dynamics and regulation by co-chaperones. Biochim Biophys Acta 2012;1823:624-35.

32. Smith DF. Dynamics of heat shock protein 90-progesterone receptor binding and the disactivation loop model for steroid receptor complexes. Mol Endocrinol 1993;7:1418-29.

33. Pratt WB, Toft DO. Regulation of signaling protein function and trafficking by the Hsp90/Hsp70-based chaperone machinery. Exp Biol Med 2003;228:111-33.

34. Riggs DL, Roberts PJ, Chirillo SC, Cheung-Flynn J, Prapapanich V, Ratajczak T, et al. The Hsp90-binding peptidylprolyl isomerase FKBP52 potentiates glucocorticoid signaling in vivo. EMBO J 2003;22:1158-67.

35. Scherrer LC, Hutchison KA, Sanchez ER, Randall SK, Pratt WB. A heat shock protein complex isolated from rabbit reticulocyte lysate can reconstitute a functional glucocorticoid receptor-Hsp90 complex. Biochemistry 1992;31:7325-9.

36. Pratt WB, Hutchison KA, Scherrer LC. Steroid receptor folding by heat-shock proteins and composition of the receptor heterocomplex. Trends Endocrinol Metab 1992;3:326-33.

37. Chen S, Smith DF. Hop as an adaptor in the heat shock protein 70 (Hsp70) and Hsp90 chaperone machinery. J Biol Chem 1998;273:35194-200.

38. Johnson BD, Schumacher RJ, Ross ED, Toft DO. Hop Modulates Hsp70/Hsp90 interactions in protein folding. J Biol Chem 1998;273:3679-86.

39. Freeman BC, Felts SJ, Toft DO, Yamamoto KR. The P23 molecular chaperones act at a late step in intracellular receptor action to differentially affect ligand efficacies. Genes Dev 2000;14:422-34.

40. Johnson JL, Toft DO. A novel chaperone complex for steroid receptors involving heat shock proteins, immunophilins, and P23. J Biol Chem 1994;269:24989-93.

41. McLaughlin SH, Sobott F, Yao ZP, Zhang W, Nielsen PR, Grossmann JG, et al. The Co-chaperone P23 arrests the Hsp90 atpase cycle to trap client proteins. J Mol Biol 2006;356:746-58.

42. Li J, Richter K, Buchner J. Mixed Hsp90-cochaperone complexes are important for the progression of the reaction cycle. Nat Struct Mol Biol 2011;18:61-6.

43. Southworth DR, Agard DA. Client-loading conformation of the Hsp90 molecular chaperone revealed in the Cryo-EM structure of the human Hsp90:Hop complex. Mol Cell 2011;42:771-81.

44. Ebong IO, Morgner N, Zhou M, Saraiva MA, Daturpalli S, Jackson SE, et al. Heterogeneity and dynamics in the assembly of the heat shock protein 90 chaperone complexes. Proc Natl Acad Sci U S A 2011;108:17939-44

45. Hu LM, Bodwell J, Hu JM, Orti E, Munck A. Glucocorticoid receptors in ATP-depleted cells. Dephosphorylation, loss of hormone binding, HSP90 dissociation, and ATP-dependent cycling. J Biol Chem 1994;269:6571-7.

46. Kosano H, Stensgard B, Charlesworth MC, Mcmahon N, Toft D. The assembly of progesterone receptor-Hsp90 complexes using purified proteins. J Biol Chem 1998;273:32973-9.

47. Fanghanel J, Fischer G. Insights into the catalytic mechanism of peptidyl prolyl Cis/Trans isomerases. Front Biosci 2004;9:3453-78.

48. Bose S, Weikl T, Bugl H, Buchner J. Chaperone function of Hsp90-associated proteins. Science 1996;274:1715-7.

49. Pirkl F, Buchner J. Functional analysis of the Hsp90-associated human peptidyl prolyl Cis/Trans isomerases FKBP51, FKBP52 and Cyp40. J Mol Biol 2001;308:795-806.

50. Freeman BC, Toft DO, Morimoto RI. Molecular chaperone machines: Chaperone activities of the cyclophilin Cyp-40 and the steroid aporeceptor-associated protein P23. Science 1996;274:1718-20.

51. Ward BK, Mark PJ, Ingram DM, Minchin RF, Ratajczak T. Expression of the estrogen receptor-associated immunophilins, cyclophilin 40 And FKBP52, in breast cancer. Breast Cancer Res Treat 1999;58:267-80.

52. Riggs DL, Cox MB, Tardif HL, Hessling M, Buchner J, Smith DF. Noncatalytic role of the FKBP52 peptidyl-prolyl isomerase domain in the regulation of steroid hormone signaling. Mol Cell Biol 2007;27:8658-69.

53. Chadli A, Bouhouche I, Sullivan W, Stensgard B, McMahon N, Catelli MG, et al. Dimerization and $\mathrm{N}$-terminal domain proximity underlie the function of the molecular chaperone heat shock protein 90. Proc Natl Acad Sci U S A 2000;97:12524-9.

54. Grenert JP, Johnson BD, Toft DO. The importance of ATP binding and hydrolysis by Hsp90 in formation and function of protein heterocomplexes. J Biol Chem 1999;274:17525-33.

55. Weikl T, Abelmann K, Buchner J. An unstructured c-terminal region of the Hsp90 co-chaperone P23 is important for its chaperone function. J Mol Biol 1999;293:685-91.

56. Weaver AJ, Sullivan WP, Felts SJ, Owen BA, Toft DO. Crystal structure and activity of human P23, A heat shock protein 90 co-chaperone. J Biol Chem 2000;275:23045-52.

57. Johnson JL, Beito TG, Krco CJ, Toft DO. Characterization of a novel 23-kilodalton protein of unactive progesterone receptor complexes. Mol Cell Biol 1994;14:1956-63.

58. Johnson JL, Toft DO. Binding of P23 and Hsp90 during assembly with the progesterone receptor. Mol Endocrinol 1995;9:670-8.

59. Obermann WM, Sondermann H, Russo AA, Pavletich NP, Hartl FU. in vivo function of Hsp90 is dependent on ATP binding and ATP hydrolysis. J Cell Biol 1998;143:901-10.

60. Panaretou B, Prodromou C, Roe SM, O`Brien R, Ladbury JE, Piper PW, et al. ATP binding and hydrolysis are essential to the function of the Hsp90 molecular chaperone in vivo. EMBO J 1998;17:4829-36.

61. Siligardi G, Hu B, Panaretou B, Piper PW, Pearl LH, Prodromou C. Co-chaperone regulation of conformational switching in the Hsp90 atpase cycle. J Biol Chem 2004;279:51989-98.

62. Richter K, Walter S, Buchner J. The co-chaperone Sba1 connects the atpase reaction of Hsp90 to the progression of the chaperone cycle. J Mol Biol 2004;342:1403-13.

63. Caplan AJ, Mandal AK, Theodoraki MA. Molecular chaperones and protein kinase quality control. Trends Cell Biol 2007;17:87-92.

64. Lee P, Shabbir A, Cardozo C, Caplan AJ. Sti1 and Cdc37 can stabilize Hsp90 in chaperone complexes with a protein kinase. Mol Biol Cell 2004;15:1785-92.

65. Gaiser AM, Kretzschmar A, Richter K. Cdc37-Hsp90 complexes

Biomed J Vol. 36 No. 3

May - June 2013 
are responsive to nucleotide-induced conformational changes and binding of further cofactors. J Biol Chem 2010;285:40921-32.

66. Maclean M, Picard D. Cdc37 goes beyond Hsp90 and kinases. Cell Stress Chaperones 2003;8:114-9.

67. Hutchison KA, Brott BK, De Leon JH, Perdew GH, Jove R, Pratt WB. Reconstitution of the multiprotein complex of Pp60src, Hsp90, and P50 in a cell-free system. J Biol Chem 1992;267:2902-8.

68. Ferguson J, Ho JY, Peterson TA, Reed SI. Nucleotide sequence of the yeast cell division cycle start genes $\mathrm{CDC} 28, \mathrm{CDC} 36, \mathrm{CDC} 37$, and CDC39, and a structural analysis of the predicted products. Nucleic Acids Res 1986;14:6681-97.

69. Reed SI. The selection of S. cerevisiae mutants defective in the start event of cell division. Genetics 1980;95:561-77.

70. Roe SM, Ali MM, Meyer P, Vaughan CK, Panaretou B, Piper PW, et al. The mechanism of Hsp90 regulation by the protein kinase-specific cochaperone P50 (Cdc37). Cell 2004;116:87-98.

71. Panaretou B, Siligardi G, Meyer P, Maloney A, Sullivan JK, Singh S, et al. Activation of the atpase activity of $\mathrm{Hsp} 90$ by the stress-regulated cochaperone Aha1. Mol Cell 2002;10:1307-18.

72. Lotz GP, Lin H, Harst A, Obermann WM. Aha1 binds to the middle domain of Hsp90, contributes to client protein activation, and stimulates the atpase activity of the molecular chaperone. J Biol Chem 2003;278:17228-35.

73. Wang X, Venable J, LaPointe P, Hutt DM, Koulov AV, Coppinger J, et al. Hsp90 cochaperone aha1 downregulation rescues misfolding of CFTR in cystic fibrosis. Cell 2006;127:803-15.

74. Li J, Richter K, Reinstein J, Buchner J. Integration of the accelerator Aha1 in the Hsp90 co-chaperone cycle. Nat Struct Mol Biol 2013;20:326-31

75. Kang H, Sayner SL, Gross KL, Russell LC, Chinkers M. Identification of amino acids in the tetratricopeptide repeat and $\mathrm{C}$-terminal domains of protein phosphatase 5 involved in autoinhibition and lipid activation. Biochemistry 2001;40:10485-90.

76. Wandinger SK, Suhre MH, Wegele H, Buchner J. The phosphatase Ppt1 is a dedicated regulator of the molecular chaperone Hsp90. EMBO J 2006;25:367-76.

77. Vaughan CK, Mollapour M, Smith JR, Truman A, Hu B, Good VM, et al. Hsp90-dependent activation of protein kinases is regulated by chaperone-targeted dephosphorylation of Cdc37. Molecular Cell 2008;31:886-95.

78. Takahashi A, Casais C, Ichimura K, Shirasu K. HSP90 interacts with RAR1 and SGT1 and is essential for RPS2-mediated disease resistance in arabidopsis. Proc Natl Acad Sci U S A 2003;100:11777-82.

79. Austin MJ, Muskett P, Kahn K, Feys BJ, Jones JD, Parker JE. Regulatory role of SGT1 in early $\mathrm{r}$ gene-mediated plant defenses. Science 2002;295:2077-80.

80. Catlett MG, Kaplan KB. Sgtlp is a unique co-chaperone that acts as a client adaptor to link Hsp90 To Skp1p. J Biol Chem 2006;281:33739-48.

81. Lee YT, Jacob J, Michowski W, Nowotny M, Kuznicki J, Chazin WJ. Human Sgt1 binds HSP90 through the CHORD-Sgt1 domain and not the tetratricopeptide repeat domain. J Biol Chem 2004;279:16511-7.

82. Kadota Y, Amigues B, Ducassou L, Madaoui H, Ochsenbein F, Guerois R, et al. Structural and functional analysis of SGT1-HSP90 core complex required for innate immunity in plants. EMBO Rep 2008;9:1209-15.
83. Kadota Y, Shirasu K. The HSP90 complex of plants. Biochim Biophys Acta 2012;1823:689-97.

84. Zhao R, Kakihara Y, Gribun A, Huen J, Yang G, Khanna M, et al. Molecular chaperone Hsp90 stabilizes Pih1/Nop17 to maintain R2TP complex activity that regulates snorna accumulation. J Cell Biol 2008;180:563-78.

85. Boulon S, Pradet-Balade B, Verheggen C, Molle D, Boireau S, Georgieva M, et al. HSP90 and its R2TP/prefoldin-like cochaperone are involved in the cytoplasmic assembly of RNA polymerase II. Mol Cell 2010;39:912-24.

86. Kakihara Y, Houry WA. The R2TP complex: Discovery and functions Biochim Biophys Acta 2012;1823:101-7.

87. Boulon S, Bertrand E, Pradet-Balade B. HSP90 and the R2TP co-chaperone complex: Building multi-protein machineries essential for cell growth and gene expression. RNA Biol 2012;9:148-54.

88. Eckert K, Saliou JM, Monlezun L, Vigouroux A, Atmane N, Caillat C, et al. The Pih1-Tah1 cochaperone complex inhibits Hsp90 molecular chaperone atpase activity. J Biol Chem 2010;285:31304-12.

89. Young JC, Hoogenraad NJ, Hartl FU. Molecular chaperones Hsp90 and $\mathrm{Hsp} 70$ deliver preproteins to the mitochondrial import receptor Tom70. Cell 2003;112:41-50.

90. Qbadou S, Becker T, Mirus O, Tews I, Soll J, Schleiff E. The molecular chaperone Hsp90 delivers precursor proteins to the chloroplast import receptor Toc64. EMBO J 2006;25:1836-47.

91. Yang Y, Yan X, Cai Y, Lu Y, Si J, Zhou T. Nudc-like protein 2 regulates the LIS1/dynein pathway by stabilizing LIS1 with Hsp90. Proc Natl Acad Sci U S A 2010;107:3499-504.

92. Crevel G, Bennett D, Cotterill S. The human TPR protein TTC4 is a putative Hsp90 co-chaperone which interacts with CDC6 and shows alterations in transformed cells. Plos One 2008;3:E0001737.

93. Mollapour M, Neckers L. Post-translational modifications of Hsp90 and their contributions to chaperone regulation. Biochim Biophys Acta 2012;1823:648-55.

94. Scroggins BT, Neckers L. Post-Translational modification of heat-shock protein 90: Impact on chaperone function. Expert Opin Drug Discov 2007;2:1403-14.

95. Shao J, Hartson SD, Matts RL. Evidence that protein phosphatase 5 functions to negatively modulate the maturation of the Hsp90-dependent heme-regulated eif2alpha kinase. Biochemistry 2002;41:6770-9.

96. Mollapour M, Tsutsumi S, Truman AW, Xu W, Vaughan CK, Beebe K, et al. Threonine 22 phosphorylation attenuates Hsp90 interaction with cochaperones and affects its chaperone activity. Mol Cell 2011;41:672-81.

97. Xu W, Mollapour M, Prodromou C, Wang S, Scroggins BT, Palchick Z, et al. Dynamic tyrosine phosphorylation modulates cycling of the HSP90-P50(CDC37)-AHA1 chaperone machine. Mol Cell 2012;47:434-43.

98. Muller P, Ruckova E, Halada P, Coates PJ, Hrstka R, Lane DP, et al. C-terminal phosphorylation of $\mathrm{Hsp} 70$ and $\mathrm{Hsp} 90$ regulates alternate binding to co-chaperones CHIP and HOP to determine cellular protein folding/degradation balances. Oncogene 2012 [Epub ahead of print].

99. Soroka J, Wandinger SK, Mäusbacher N, Schreiber T, Richter K, Daub $\mathrm{H}$, et al. Conformational switching of the molecular chaperone Hsp90 via regulated phosphorylation. Mol Cell 2012;45:517-28.

100. Mollapour M, Tsutsumi S, Donnelly AC, Beebe K, Tokita MJ, Lee MJ, et al. Swe1Wee1-dependent tyrosine phosphorylation of 
Hsp90 regulates distinct facets of chaperone function. Mol Cell 2010;37:333-43.

101. Miyata Y. Protein kinase CK2 in health and disease: CK2: The kinase controlling the Hsp90 chaperone machinery. Cell Mol Life Sci 2009;66:1840-9.

102. Duval M, Le BF, Huot J, Gratton JP. Src-mediated phosphorylation of Hsp90 in response to Vascular Endothelial Growth Factor (VEGF) is required for VEGF receptor-2 signaling to endothelial NO synthase. Mol Biol Cell 2007;18:4659-68.

103. Lei H, Venkatakrishnan A, Yu S, Kazlauskas A. Protein kinase A-dependent translocation of Hsp90 alpha impairs endothelial nitric-oxide synthase activity in high glucose and diabetes. J Biol Chem 2007;282:9364-71.

104. Aoyagi S, Archer TK. Modulating molecular chaperone Hsp90 functions through reversible acetylation. Trends Cell Biol $2005 ; 15: 565-7$.

105. Yang Y, Rao R, Shen J, Tang Y, Fiskus W, Nechtman J, et al. Role of acetylation and extracellular location of heat shock protein 90alpha in tumor cell invasion. Cancer Res 2008;68:4833-42.

106. Kekatpure VD, Dannenberg AJ, Subbaramaiah K. HDAC6 modulates Hsp90 chaperone activity and regulates activation of aryl hydrocarbon receptor signaling. J Biol Chem 2009;284:7436-45.

107. Kovacs JJ, Murphy PJ, Gaillard S, Zhao X, Wu JT, Nicchitta CV, et al. HDAC6 regulates Hsp90 acetylation and chaperone-dependent activation of glucocorticoid receptor. Mol Cell 2005;18:601-7.

108. Scroggins BT, Robzyk K, Wang D, Marcu MG, Tsutsumi S, Beebe K, et al. An acetylation site in the middle domain of Hsp90 regulates chaperone function. Mol Cell 2007;25:151-9.

109. Scroggins BT, Neckers L. Just say NO: Nitric oxide regulation of Hsp90. EMBO Rep 2009;10:1093-4.

110. Hess DT, Matsumoto A, Kim SO, Marshall HE, Stamler JS. Protein S-nitrosylation: Purview and parameters. Nat Rev Mol Cell Biol 2005;6:150-66.

111. Martínez-RuizA, Villanueva L, González de Orduña C, López-Ferrer D, Higueras MA, Tarín C, et al. S-Nitrosylation of Hsp90 promotes the inhibition of its atpase and endothelial nitric oxide synthase regulatory activities. Proc Natl Acad Sci U S A 2005;102:8525-30.

112. Retzlaff M, Stahl M, Eberl HC, Lagleder S, Beck J, Kessler H, et al. Hsp90 is regulated by a switch point in the $\mathrm{C}$-terminal domain. EMBO Rep 2009;10:1147-53.

113. Momose F, Naito T, Yano K, Sugimoto S, Morikawa Y, Nagata K. Identification of Hsp90 as a stimulatory host factor involved in influenza virus RNA synthesis. J Biol Chem 2002;277:45306-14.

114. Mayor A, Martinon F, De Smedt T, Petrilli V, Tschopp J. A crucial function of SGT1 and HSP90 in inflammasome activity links mammalian and plant innate immune responses. Nat Immunol 2007;8:497-503.

115. Pratt WB, Morishima Y, Peng HM, Osawa Y. Proposal for a role of the Hsp90/Hsp70-Based chaperone machinery in making triage decisions when proteins undergo oxidative and toxic damage. Exp Biol Med 2010;235:278-89.

116. Picard D, Khursheed B, Garabedian MJ, Fortin MG, Lindquist S, Yamamoto KR. Reduced levels of Hsp90 compromise steroid receptor action in vivo. Nature 1990;348:166-8.

117. Whittier JE, Xiong Y, Rechsteiner MC, Squier TC. Hsp90 enhances degradation of oxidized calmodulin by the $20 \mathrm{~S}$ proteasome. J Biol Chem 2004;279:46135-42.

Biomed J Vol. 36 No. 3

May - June 2013
118. Li R, Soosairajah J, Harari D, Citri A, Price J, Ng HL, et al. Hsp90 increases LIM Kinase activity by promoting its homo-dimerization. FASEB J 2006;20:1218-20

119. Citri A, Harari D, Shohat G, Ramakrishnan P, Gan J, Lavi S, et al. Hsp90 recognizes a common surface on client kinases. J Biol Chem 2006;281:14361-9.

120. Gould CM, Kannan N, Taylor SS, Newton AC. The chaperones Hsp90 and $\mathrm{Cdc} 37$ mediate the maturation and stabilization of protein kinase $\mathrm{C}$ through A conserved PXXP motif in the C-terminal tail. J Biol Chem 2009;284:4921-35.

121. Terasawa K, Yoshimatsu K, Iemura S, Natsume T, Tanaka K, Minami Y. Cdc37 interacts with the glycine-rich loop of Hsp90 client kinases. Mol Cell Biol 2006;26:3378-89.

122. Xu Y, Singer MA, Lindquist S. Maturation of the tyrosine kinase C-Src as a kinase and as a substrate depends on the molecular chaperone Hsp90. Proc Natl Acad Sci U S A 1999;96:109-14.

123. Falsone SF, Leptihn S, Osterauer A, Haslbeck M, Buchner J. Oncogenic mutations reduce the stability of SRC kinase. J Mol Biol 2004;344:281-91.

124. Muller P, Ceskova P, Vojtesek B. Hsp90 is essential for restoring cellular functions of temperature-sensitive P53 mutant protein but not for stabilization and activation of wild-type P53: Implications for cancer therapy. J Biol Chem 2005;280:6682-91.

125. Walerych D, Kudla G, Gutkowska M, Wawrzynow B, Muller L, King FW, et al. Hsp90 chaperones wild-type P53 tumor suppressor protein. J Biol Chem 2004;279:48836-45.

126. Muller L, Schaupp A, Walerych D, Wegele H, Buchner J. Hsp90 regulates the activity of wild type P53 under physiological and elevated temperatures. J Biol Chem 2004;279:48846-54.

127. Walerych D, Gutkowska M, Klejman MP, Wawrzynow B, Tracz Z, Wiech M, et al. ATP binding to Hsp90 is sufficient for effective chaperoning of P53 protein. J Biol Chem 2010;285:32020-8

128. Rudiger S, Freund SM, Veprintsev DB, Fersht AR. CRINEPT-TROSY NMR reveals $\mathrm{p} 53$ core domain bound in an unfolded form to the chaperone Hsp90. Proc Natl Acad Sci U S A 2002;99:11085-90.

129. Park SJ, Borin BN, Martinez-Yamout MA, Dyson HJ. The client protein P53 adopts a molten globule-like state in the presence of Hsp90. Nat Struct Mol Biol 2011;18:537-41.

130. Hagn F, Lagleder S, Retzlaff M, Rohrberg J, Demmer O, Richter K, et al. structural analysis of the interaction between Hsp90 and the tumor suppressor protein P53. Nat Struct Mol Biol 2011;18:1086-93.

131. Goasduff T, Cederbaum AI. CYP2E1 degradation by in vitro reconstituted systems: Role of the molecular chaperone Hsp90. Arch Biochem Biophys 2000;379:321-30.

132. Fuller W, Cuthbert AW. Post-translational disruption of the delta F508 cystic fibrosis transmembrane conductance regulator (CFTR)-molecular chaperone complex with geldanamycin stabilizes delta F508 CFTR in the rabbit reticulocyte lysate. J Biol Chem 2000;275:37462-8.

133. Gusarova V, Caplan AJ, Brodsky JL, Fisher EA. Apoprotein B degradation is promoted by the molecular chaperones Hsp90 and Hsp70. J Biol Chem 2001;276:24891-900.

134. Ballinger CA, Connell $\mathrm{P}, \mathrm{Wu} \mathrm{Y}, \mathrm{Hu} \mathrm{Z}$, Thompson LJ, Yin LY, et al. Identification of CHIP, a novel tetratricopeptide repeat-containing protein that interacts with heat shock proteins and negatively regulates chaperone functions. Mol Cell Biol 1999;19:4535-45. 
135. Connell P, Ballinger CA, Jiang J, Wu Y, Thompson LJ, Höhfeld J, et al. The co-chaperone CHIP regulates protein triage decisions mediated by heat-shock proteins. Nat Cell Biol 2001;3:93-6.

136. Meacham GC, Patterson C, Zhang W, Younger JM, Cyr DM. The Hsc70 co-chaperone CHIP targets immature CFTR for proteasomal degradation. Nat Cell Biol 2001;3:100-5.

137. Sanchez ER, Toft DO, Schlesinger MJ, Pratt WB. Evidence that the 90-Kda phosphoprotein associated with the untransformed L-Cell glucocorticoid receptor is a murine heat shock protein. J Biol Chem $1985 ; 260: 12398-401$.

138. Fan M, Park A, Nephew KP. CHIP (Carboxyl Terminus Of Hsc70-Interacting Protein) promotes basal and geldanamycin-induced degradation of estrogen receptor-alpha. Mol Endocrinol 2005;19:2901-14.

139. Xu W, Marcu M, Yuan X, Mimnaugh E, Patterson C, Neckers L. Chaperone-dependent E3 ubiquitin ligase CHIP mediates a degradative pathway for C-Erbb2/Neu. Proc Natl Acad Sci U S A 2002;99:12847-52.

140. Ehrlich ES, Wang T, Luo K, Xiao Z, Niewiadomska AM, Martinez T, et al. Regulation of Hsp90 client proteins by a Cullin5-RING E3 ubiquitin ligase. Proc Natl Acad Sci U S A 2009;106:20330-5.

141. Mandal AK, Gibney PA, Nillegoda NB, Theodoraki MA, Caplan AJ, Morano KA. Hsp110 chaperones control client fate determination in the Hsp70-Hsp90 chaperone system. Mol Biol Cell 2010;21:1439-48.

142. Nanbu K, Konishi I, Mandai M, Kuroda H, Hamid AA, Komatsu T, et al. Prognostic significance of heat shock proteins HSP70 and HSP90 in endometrial carcinomas. Cancer Detect Prev 1998;22:549-55.

143. Liu XL, Xiao B, Yu ZC, Guo JC, Zhao QC, Xu L, et al. Down-regulation of Hsp90 could change cell cycle distribution and increase drug sensitivity of tumor cells. World J Gastroenterol 1999;5:199-208.

144. Neckers L, Mimnaugh E, Schulte TW. Hsp90 as an anti-cancer target. Drug Resist Updat 1999;2:165-72.

145. Yano M, Naito Z, Yokoyama M, Shiraki Y, Ishiwata T, Inokuchi M, et al. Expression of Hsp90 and cyclin D1 in human breast cancer. Cancer Lett 1999; 137:45-51.

146. Ferrarini M, Heltai S, Zocchi MR, Rugarli C. Unusual expression and localization of heat-shock proteins in human tumor cells. Int J Cancer 1992;51:613-9.

147. Trepel J, Mollapour M, Giaccone G, Neckers L. Targeting the dynamic HSP90 complex in cancer. Nat Rev Cancer 2010;10:537-49.

148. Neckers L, Workman P. Hsp90 molecular chaperone inhibitors: Are we there yet? Clin Cancer Res 2012;18:64-76.

149. Stebbins CE, Russo AA, Schneider C, Rosen N, Hartl FU, Pavletich NP. Crystal structure of an Hsp90-geldanamycin complex: Targeting of a protein chaperone by an antitumor agent. Cell 1997;89:239-50.
150. Whitesell L, Mimnaugh EG, De Costa B, Myers CE, Neckers LM. Inhibition of heat shock protein HSP90-Pp60v-Src heteroprotein complex formation by benzoquinone ansamycins: Essential role for stress proteins in oncogenic transformation. Proc Natl Acad Sci USA 1994;91:8324-8.

151. Supko JG, Hickman RL, Grever MR, Malspeis L. Preclinical pharmacologic evaluation of geldanamycin as an antitumor agent. Cancer Chemother Pharmacol 1995;36:305-15.

152. Niikura Y, Ohta S, Vandenbeldt KJ, Abdulle R, Mcewen BF, Kitagawa K. 17-AAG, an Hsp90 inhibitor, causes kinetochore defects: A novel mechanism by which 17-AAG inhibits cell proliferation. Oncogene 2006;25:4133-46.

153. Schulte TW, Neckers LM. The benzoquinone ansamycin 17-Allylamino-17-demethoxygeldanamycin binds to HSP90 and shares important biologic activities with geldanamycin. Cancer Chemother Pharmacol 1998;42:273-9.

154. Schulte TW, Akinaga S, Soga S, Sullivan W, Stensgard B, Toft D, et al. Antibiotic radicicol binds to the N-terminal domain of Hsp90 and shares important biologic activities with geldanamycin. Cell Stress Chaperones 1998;3:100-8.

155. Kwon HJ, Yoshida M, Fukui Y, Horinouchi S, Beppu T. Potent and specific inhibition of $\mathrm{P} 60 \mathrm{v}-\mathrm{Src}$ protein kinase both in vivo and in vitro by radicicol. Cancer Res 1992;52:6926-30.

156. Sreedhar AS, Soti C, Csermely P. Inhibition of Hsp90: A new strategy for inhibiting protein kinases. Biochim Biophys Acta 2004; 1697:233-42.

157. Clevenger RC, Blagg BS. Design, synthesis, and evaluation of a radicicol and geldanamycin chimera, radamide. Org Lett 2004;6:4459-62.

158. Chiosis G, Timaul MN, Lucas B, Munster PN, Zheng FF, Sepp-Lorenzino $\mathrm{L}$, et al. A small molecule designed to bind to the adenine nucleotide pocket of $\mathrm{Hsp} 90$ causes her 2 degradation and the growth arrest and differentiation of breast cancer cells. Chem Biol 2001;8:289-99.

159. Marcu MG, Schulte TW, Neckers L. Novobiocin and related coumarins and depletion of heat shock protein 90 -dependent signaling proteins. J Natl Cancer Inst 2000;92:242-8.

160. Soti C, Racz A, Csermely P. A nucleotide-dependent molecular switch controls ATP binding at the C-terminal domain of Hsp90. N-terminal nucleotide binding unmasks a C-terminal binding pocket. J Biol Chem 2002;277:7066-75

161. Sgobba M, Forestiero R, Degliesposti G, Rastelli G. Exploring the binding site of C-terminal Hsp90 inhibitors. J Chem Inf Model 2010;50:1522-8

162. Kim YS, Alarcon SV, Lee S, Lee MJ, Giaccone G, Neckers L, et al. Update on Hsp90 inhibitors in clinical trial. Curr Top Med Chem 2009;9:1479-92.0. 